\title{
How members of the public interpret the word accident
}

\author{
D C Girasek
}

\begin{abstract}
Objective-To explore what the word accident means to the lay public. This interpretation is of interest because it has been raised by injury control professionals as one justification for discouraging use of that word.

Methods-A national telephone survey of 943 adults in the United States was conducted. Respondents were selected at random from households whose phone numbers were generated using random digit dialing techniques. Bivariate and multivariate analyses were performed to determine if respondent characteristics predicted their interpretations of the word accident.

Results-Eighty three per cent of respondents associated preventability with the word accident, and only $26 \%$ felt that accidents were controlled by fate. However, $71 \%$ thought that accidents could not be predicted, and $4 \%$ felt that accidents were done on purpose. Age, education, income, and race emerged as independent predictors of various accident interpretations.

Conclusions-Only in the case of "unpredictability" does the public's interpretation of the word accident match many experts' expectations. The concept of "unintentionality" is what seems to be communicated most strongly by use of the word accident. Persistent attempts on the part of injury control professionals to eliminate this word from social discourse may result in unintended consequences, which are discussed.

(Injury Prevention 1999;5:19-25)
\end{abstract}

Keywords: accident; public; national survey; terminology

Preventive Medicine and Biometrics, Uniformed Services University of the Health Sciences, 4301 Jones Bridge Road, Room A2060, Bethesda, MD 20814, USA

Correspondence to: Dr Girasek, Assistant Professor (e-mail: Dgirasek@usuhs.mil).

North American injury control professionals eschew the word accident. They believe it reinforces public misconceptions that injuries cannot be predicted or prevented, or that injuries are controlled by fate. This concern has been raised by numerous leaders of the modern injury prevention movement:

- The term accident...is an inaccurate anachronism reflecting unscientific attitudes towards injuries. $^{1}$
- The magnitude of the automotive injury problem in the pediatric population remains as great as it is largely because of the perpetuation of a societal ethic that automotive injuries are "accidents". The word "accident" suggests that the injury event was determined by fate and, therefore, was unpredictable and unavoidable. ${ }^{2}$

-... another critical element in understanding injuries in America [is] the extent to which their occurrence is affected by people's attitudes. Perhaps the most pervasive of these - what Haddon, Suchman, and Klein called "the last folklore subscribed to by rational men"-is the belief that injuries are "accidents".

The United States' National Highway Traffic Safety Administration recently banned its employees from using the word accident in official communication, claiming its use "promotes the concept that these events are outside of human influence or control". ${ }^{4}$ Representatives of a number of safety related organizations have endorsed this campaign to "eliminate the word 'accident' from the realm of unintentional injury...across the nation....and in all public contexts". This debate has also been aired in this journal. ${ }^{56}$

Rarely, however, is empirical evidence presented to support claims of what the word accident means to the public. Ironically, professionals' assertion - that lay individuals embrace pre-scientific concepts of injury causationdoes not itself appear to be data driven.

\section{Background}

Only one previous national (American) study of this topic has been identified in the literature, and it dealt with childhood injuries. In it, a telephone survey of 404 parents, $87 \%$ agreed with the statement "most accidents are preventable". ${ }^{7}$ The authors characterized this finding as "parents' overwhelming rejection of the notion that accidents just happen". Revealingly, subjects' responses were not affected by whether the word "injury" or "accident" was used in the question.

In a British study of urban mothers, $89 \%$ of respondents $(n=80)$ responded, "mostly could children's accidents are mostly just bad luck or mostly could be prevented?" In an in-depth study of one low income neighborhood in Glasgow, $61 \%$ of parents disagreed with the be prevented", when asked "Do you think that 
statement "There's nothing you can do to stop accidents. They just happen". ${ }^{9}$

Canadian researchers, who used random digit dialing to interview 1516 parents, found that $82 \%$ of urban respondents and $91 \%$ of semirural respondents agreed with the statement "Most accidents are avoidable, parents can prevent most accidental injuries involving children". ${ }^{10}$

When the attitudes of a group of coal miners in the United States were compared with those of other industrial workers $(n=66), 84 \%$ of the miners, and $85 \%$ of the non-miners, felt that "accidents are caused, they do not just happen". ${ }^{11}$

Two qualitative studies carried out in Great Britain found, "no evidence of specifically 'lay' beliefs in the random nature of accidents, or a belief that they were generally unpreventable"..$^{12}$

While other studies have examined beliefs about the preventability of injuries or a particular "accident", those just cited queried subjects about accident generically. We know of no national studies focusing on the meaning of the word accident. Of interest is the fact that more than 30 years ago Suchman called for more research into, "the social psychological function" and 'meaning' of accidents". ${ }^{13}$

The data that follow are from a larger study that examined public beliefs regarding fatal injury preventability. This report deals specifically with subjects' interpretations of the word accident.

\section{Subjects}

GENESYS Sampling Systems (a commercial supplier) provided a sample of telephone numbers that were generated using random digit dialing techniques. This sampling strategy was designed to achieve a nationally representative sample of United States households.

\section{Methods}

INSTRUMENT DEVELOPMENT

Focus groups were conducted before survey development to learn how subjects understood words like, "accident", "injury-producing event", etc. It was determined from this process

\section{Starting \\ sample \\ 6761}
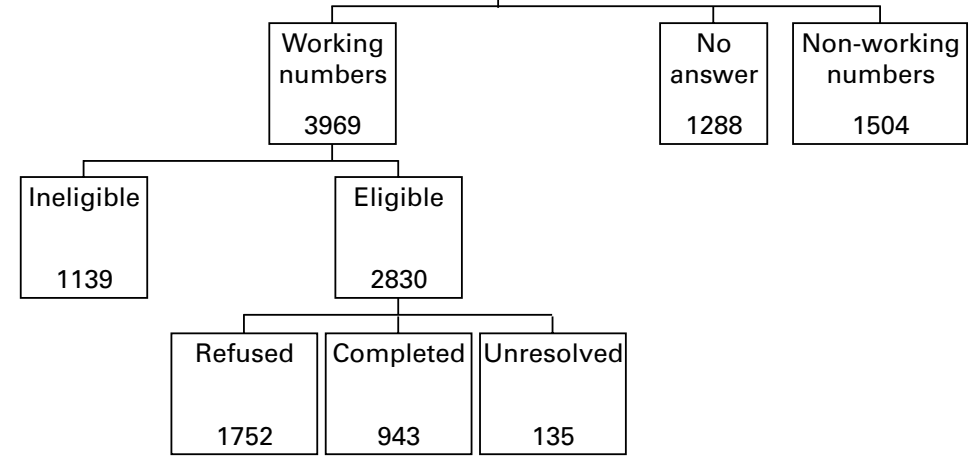

Figure 1 Disposition of sample. that the term, "random", would not be included in the survey instrument because it yielded varied and sometimes conflicting interpretations. When a draft instrument was developed, cognitive interviews were conducted. This technique calls for subjects to complete the questionnaire item-by-item, explaining to the investigator why they chose the answer they did. It reveals how questions and response categories are being interpreted, and has been demonstrated to reduce reporting error. ${ }^{14} \mathrm{~A}$ small pilot study was then carried out, by telephone, to test the survey protocol.

SURVEY PROTOCOL

When the measure was considered to be in final form it was converted to CATI (computer assisted telephone interviewing) format. Interviewers from a market research firm were then trained by the investigator to administer the questionnaire.

At least six attempts were made to reach each telephone number in the sample. Calls were scheduled so that at least one attempt was made on a weekday, a weeknight, and a weekend. All phone numbers were tried for more than a one week period. Data collection took place between 19 August and 3 October 1996.

Only private (non-commercial, noninstitutional) households were eligible for inclusion in this study. Subjects also had to be English speaking. One respondent, aged 18 or over, was selected at random (using the most recent birthday method) from each eligible household. Informed consent was then obtained.

MEASURES

This section of the questionnaire used the following preface:

For the next questions, I want to explain that when I say "accident", I don't just mean car accidents. I want you to consider car accidents, but also falls, drownings, fires, burns, and accidental poisonings.

Subjects were then asked:

- When you hear the word "accident", do you usually think that what happened could have been prevented, or not?

- When you hear the word "accident", do you usually think that what happened could have been predicted, or not?

- When you hear the word "accident", do you usually think that what happened was controlled by fate, or not?

- When you hear the word "accident," do you usually think that what happened was done on purpose, or not?

The demographic variables measured include age, gender, household income, education, race, and Hispanic origin. Religiosity, risk taking proclivity, and personal injury history were also assessed. The religiosity and risk taking items were prefaced with the phrase, "The next few questions have to do with how you would describe yourself". Interviewers went on to ask, "Would you say that you are religious, somewhat religious, or not religious?" Risk taking proclivity was assessed with the question, 
Table 1 Comparison of study sample and United States population

\begin{tabular}{|c|c|c|}
\hline Variable & $\begin{array}{l}\text { Sample } \\
\text { proportion } \\
(\%)\end{array}$ & $\begin{array}{l}\text { United States } \\
\text { census proportion } \\
(\%)\end{array}$ \\
\hline \multicolumn{3}{|l|}{ Age $(n=863)$} \\
\hline $18-39$ & 44 & 45 \\
\hline $40-64$ & 39 & 37 \\
\hline$\geqslant 65$ & 17 & 17 \\
\hline \multicolumn{3}{|l|}{ Gender $(n=943)$} \\
\hline Female & 63 & 52 \\
\hline Male & 37 & 48 \\
\hline \multicolumn{3}{|c|}{ Household income $(n=821)$} \\
\hline$<\$ 10000$ & 5 & 14 \\
\hline $10000-14999$ & 10 & 9 \\
\hline $15000-24999$ & 16 & 17 \\
\hline $25000-34999$ & 22 & 14 \\
\hline $35000-49999$ & 21 & 16 \\
\hline $50000-74999$ & 15 & 17 \\
\hline$\geqslant 75000$ & 11 & 14 \\
\hline \multicolumn{3}{|l|}{ Education $(n=939)$} \\
\hline \multicolumn{3}{|l|}{ Not a high school } \\
\hline High school graduate & 34 & $\begin{array}{l}19 \\
34\end{array}$ \\
\hline Some college & 28 & 27 \\
\hline College graduate & 15 & 14 \\
\hline Advanced degree & 12 & 7 \\
\hline \multicolumn{3}{|l|}{ Race $(n=886)$} \\
\hline White & 85 & 84 \\
\hline African-American & 11 & 12 \\
\hline Asian/Pacific Islander & 2 & 4 \\
\hline \multicolumn{3}{|l|}{ Native American/Alaska } \\
\hline Native & 2 & 1 \\
\hline \multicolumn{3}{|l|}{ Hispanic origin $(n=934)$} \\
\hline Yes & 6 & 9 \\
\hline No & 95 & 91 \\
\hline \multicolumn{3}{|l|}{ Geographic region $(n=943)$} \\
\hline Northeast & 17 & 20 \\
\hline Midwest & 26 & 24 \\
\hline South & 39 & 35 \\
\hline West & 18 & 21 \\
\hline
\end{tabular}

"How often would you say that you like to do things that other people consider dangerous?" Response options included; "always", "often", "rarely", and "never". Personal injury history was measured by responses to, "Have you ever had to stay overnight in a hospital as a result of being in a motor vehicle crash, a fall, a near-drowning, a fire or burns, or accidental poisoning?"

STATISTICAL ANALYSES

Data were analyzed using SPSS 7.5 for Windows statistical software; $\chi^{2}$ tests of association were conducted to determine whether subjects' interpretations of the word accident were independent of their personal attributes. When necessary to achieve adequate cell sizes, "don't know" and "refused" responses to these items were dropped from bivariate analyses.

To determine which variables were independently related to differing interpretations of the word "accident", multivariate analyses were conducted. Variables whose bivariate tests of association yielded $p$ values of at least 0.25 were entered into four logistic regression models predicting the dependent variables: preventable, predictable, "controlled by fate", and "done on purpose". Subjects responding "don't know" to the items representing dependent variables (that is interpretations of the word accident) were excluded from these analyses.

\section{Results}

SAMPLE

Our total sample of telephone numbers was 6761. The disposition of that sample at the end

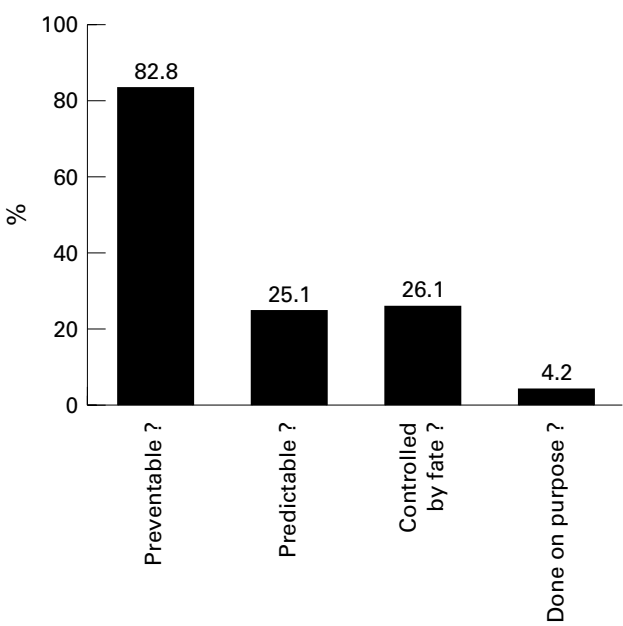

Figure 2 Proportion of subjects endorsing displayed meaning of the word "accident" $(n=943)$.

of data collection is presented in fig 1 . Phone numbers were categorized as unresolved if no final determination of their status could be made within the data collection period. The response rate was $35 \%$ if only resolved households known to be eligible are included in the denominator.

Table 1 summarizes how subjects' self reports of demographic data compare with the United States' population. Population parameters were derived from the Bureau of the Census.

The sample's breakdown with regard to risk taking proclivity, personal injury history, and religiosity follows. When asked how often they like to do things that other people consider dangerous, $2.8 \%$ of (943) subjects said "always", $12.8 \%$ said "often", $48.5 \%$ said "rarely", $34.9 \%$ said "never", and $1 \%$ of subjects said "don't know" or refused to answer. Nearly one fifth $(18.9 \%)$ of subjects reported having been hospitalized due to one of the injury events under study. Forty eight per cent of subjects said they were religious, $40.4 \%$ said they were somewhat religious, $10 \%$ said they were not religious, and $1.3 \%$ said they didn't know if they were religious or refused to answer the question.

SUMMARY OF FINDINGS

Figure 2 displays the proportion of subjects who responded in the affirmative when asked if they usually associated a given meaning with the word accident. Fewer than 5\% of subjects responded "don't know" to these questions.

When bivariate analyses were conducted, believing that accidents were preventable did not differ significantly by age, gender, income, education, race, Hispanic origin, religiosity, risk taking proclivity, or personal injury history.

Believing that accidents were predictable also did not differ significantly by most variables, though it did for education. Subjects with college or graduate degrees were significantly more likely to associate predictability with the word accident.

Believing that accidents were controlled by fate differed significantly by age, race, income, and education. Respondents who were under 
Table 2 Logistic regression results: interpretations of the word accident

\begin{tabular}{|c|c|c|c|c|}
\hline Variable & $\begin{array}{l}\text { Preventable odds ratio } \\
(95 \% \text { CI) }\end{array}$ & $\begin{array}{l}\text { Predictable odds ratio } \\
(95 \% \mathrm{CI})\end{array}$ & $\begin{array}{l}\text { Controlled by fate odds } \\
\text { ratio }(95 \% \text { CI) }\end{array}$ & $\begin{array}{l}\text { Done on purpose odds } \\
\text { ratio }(95 \% \text { CI) }\end{array}$ \\
\hline \multicolumn{5}{|l|}{ Age } \\
\hline $18-39$ & $0.50(0.24$ to 1.02$)$ & & $1.97^{\star \star}(1.15$ to 3.38$)$ & $0.47(0.18$ to 1.22$)$ \\
\hline $40-64$ & $0.49^{\star}(0.24$ to 1.01$)$ & & $1.30(0.75$ to 2.27$)$ & $0.57(0.22$ to 1.47$)$ \\
\hline$\geqslant 65$ & 1.00 & & 1.00 & 1.00 \\
\hline \multicolumn{5}{|l|}{ Gender } \\
\hline Male & & $1.15(0.84$ to 1.59$)$ & $0.79(0.55$ to 1.13$)$ & \\
\hline Female & & 1.00 & 1.00 & \\
\hline \multicolumn{5}{|l|}{ Education } \\
\hline Not a high school graduate & $1.49(0.60$ to 3.72$)$ & $0.80(0.41$ to 1.56$)$ & $2.59^{\star}(1.18$ to 5.67$)$ & \\
\hline High school graduate & $1.47(0.78$ to 2.79$)$ & $0.60^{\star}(0.36$ to 0.99$)$ & $1.87^{\star}(1.02$ to 3.46$)$ & \\
\hline Some college & $0.98(0.52$ to 1.83$)$ & $0.60^{\star}(0.36$ to 1.00$)$ & $1.51(0.81$ to 2.81$)$ & \\
\hline College graduate & $1.34(0.64$ to 2.81$)$ & $0.85(0.49$ to 1.48$)$ & $1.03(0.50$ to 2.10$)$ & \\
\hline Advanced degree & 1.00 & 1.00 & 1.00 & \\
\hline \multicolumn{5}{|l|}{ Household income } \\
\hline$<\$ 25000$ & & $0.82(0.56$ to 1.19$)$ & $1.32(0.91$ to 1.94$)$ & $2.44^{\star}(1.14$ to 5.22$)$ \\
\hline$>\$ 25000$ & & 1.00 & 1.00 & 1.00 \\
\hline \multicolumn{5}{|l|}{ Race } \\
\hline African-American & 0.71 (0.39 to 1.28$)$ & & $2.02^{\star \star}(1.22$ to 3.37$)$ & $2.53^{\star}(1.03$ to 6.20$)$ \\
\hline Other (non-white) & $1.57(0.65$ to 3.75$)$ & & $1.18(0.64$ to 2.19$)$ & $0.95(0.21$ to 4.26$)$ \\
\hline White & 1.00 & & 1.00 & 1.00 \\
\hline \multicolumn{5}{|l|}{ Religious } \\
\hline Yes & & & $1.38(0.74$ to 2.57$)$ & \\
\hline Somewhat & & & $1.48(0.79$ to 2.77$)$ & \\
\hline No & & & 1.00 & \\
\hline \multicolumn{5}{|l|}{ Risk taking } \\
\hline Always & & & $1.45(0.51$ to 4.10$)$ & $3.99(0.93$ to 17.17$)$ \\
\hline Often & & & $1.44(0.84$ to 2.46$)$ & $1.66(0.59$ to 4.68$)$ \\
\hline Rarely & & & $0.91(0.61$ to 1.33$)$ & $0.61(0.25$ to 1.47$)$ \\
\hline Never & & & 1.00 & 1.00 \\
\hline \multicolumn{5}{|l|}{ Injury history } \\
\hline Yes & & $1.22(0.83$ to 1.80$)$ & 1.37 (0.90 to 2.07$)$ & \\
\hline No & & 1.00 & 1.00 & \\
\hline
\end{tabular}

$\mathrm{CI}=$ confidence interval.

${ }^{\star} \mathrm{p} \leqslant 0.05 ;{ }^{\star \star} \mathrm{p} \leqslant 0.01$.

the age of 40, African-American, had household incomes of less than $\$ 25000$ per year, or had less than a college degree were more likely to report that when they heard the word accident they usually thought that what happened was controlled by fate.

Believing that accidents were done on purpose differed significantly by race and income. Non-white subjects and those from households with incomes under $\$ 25000$ per year were more likely to associate intentionality with the word accident.

The findings yielded by logistic regression are presented in table 2 . Age was the only significant predictor of whether subjects interpreted accident as meaning preventable. People under the age of 65 were approximately half as likely as older respondents to say that when they heard the word accident they usually thought that what happened could have been prevented. Education was a significant predictor of predictability interpretations, with subjects who had earned at least a high school diploma but less than a college degree being about $40 \%$ less likely than subjects with a graduate degree to say that they usually thought accidents could be predicted. Education also emerged as a significant predictor of subjects' fate related interpretations of accident, as did age and race. Subjects with no college education were two to three times more likely than subjects with graduate degrees to think that accidents were controlled by fate. Subjects under the age of 40 (when compared with those aged 65 or older), and African-American subjects (when compared with white people), had approximately double the likelihood of holding fatalistic interpretations of accident. African-Americans were also more than twice as likely to associate intentionality with the word accident, and subjects from low income households were 2.4 times more likely than wealthier respondents to think that accidents were "done on purpose".

\section{Discussion}

Thinking about the word accident evoked notions of preventability for $83 \%$ of our subjects. Approximately three quarters of respondents did not associate fatalism with the word accident. These findings would probably come as no surprise to social psychologists. It is threatening for people to believe that misfortune is random; that there is nothing they can do to prevent bad things from happening to themselves or the people they care for.

The relatively high levels of preventability beliefs associated with the word accident may, in the minds of public health professionals, seem to contradict the fact that only $25 \%$ of subjects thought that events described as accidents could usually be predicted. Statistical predictions underpin most preventive recommendations. Indeed, John Last's A Dictionary of Epidemiology states in its definition of the word accident, "Epidemiologic studies have demonstrated that the risk of accidents is often predictable; they are therefore preventable" (emphasis added). ${ }^{15}$

This discrepancy may stem from the fact that members of the public health community view injuries from a different vantage point than do members of the public. It is a question of scale: the aggregate versus the individual. Epidemiology's power to predict rare events diminishes as the size of the population under study decreases. The risk factors researchers have 
identified tell us which constellation of personal and environmental characteristics make a fatal injury more probable. We are nowhere near being able to identify which individuals will die, however, or when such deaths will take place. Meanwhile, members of the public see everyday that the majority of those who ignore safety recommendations die from causes other than injury. That leaves a considerable amount of unexplained variance, and it may be why respondents continue to regard "accidents" as unpredictable.

Should we be concerned with this seeming non sequitur? Davison and colleagues credit the public with realizing that "randomness and chance are deeply involved in the intersection of individual lives and general rules". ${ }^{16}$ They note that cultural systems for explaining misfortune must address two distinct issues: how and why misfortune happens, and how and why it happened "to this person at this time". ${ }^{17}$ With regard to cardiac disease, Davison's group found that subjects' fatalistic explanations concerned disease distribution. When discussing the causes of heart disease, respondents' explanations referred to human behavior. ${ }^{16}$ Roberts et al found that the minority of their respondents who did hold fatalistic views with regard to children's injuries "did so more as a coping mechanism...than as a substitute for preventive action". 9 So while injury control professionals look to patterns of injury occurrence for preventive strategies, lay individuals may be capable of adopting preventive behaviors in the absence of predictability.

It should also be acknowledged that public interpretations do not run totally counter to what professionals, indeed to what logic, might dictate. Subjects' interpretations were not independent of each other. People who thought accidents were predictable were significantly more likely to think they were preventable. Subjects who thought accidents were controlled by fate were less likely to believe they were preventable. Those who deemed accidents done on purpose were more likely to describe them as predictable. Thus anticipated relationships do seem to exist between types of accident beliefs. But what is the relationship between accidents and beliefs?

None of the accident interpretations explored in this study were associated with having been hospitalized for an injury. This lends support to the notion that beliefs related to the word accident may be independent of injury risk. Several known risk factors for injury, however, were found to be predictive of accident interpretations that run counter to professional preferences. Younger subjects were less likely to associate preventability with accident, and more likely to believe that such events were controlled by fate. Subjects with less education were less likely to associate predictability with accident, and more likely to believe that accidents were controlled by fate. AfricanAmerican subjects were also more likely to associate fatalism with the word accident. African-American respondents and low income respondents were more likely to think that accidents were "done on purpose". Unfor- tunately, a cross sectional study such as this cannot determine whether accident beliefs result in, or result from, increased injury risk.

The meaning of "accident" which garnered the largest plurality (94\%) in this study was: "not done on purpose". While this interpretation might not surprise injury control professionals, they tend to ignore it in their admonitions to abandon the word. This finding seems to imply, however, that statements like, "injuries aren't accidents" may engender sentiments of victim blaming. In a sociologic analysis of how accidents have been approached through the ages, the prospects for injured people being received with sympathy at the end of the 20th century are described as, "bleak". ${ }^{12}$ Indeed, there have been calls to discontinue "euphemisms" like accident so we can "place responsibility where it belongs". ${ }^{18}$ To be fair, we should note that most injury control practitioners prefer preventive strategies that do not rely on individual compliance.

Still, efforts to increase public perceptions of injury preventability may, inadvertently, decrease the support afforded accident survivors. ${ }^{19} 20$ Injury prevention advocates in Arizona have noted that parents of young drowning victims are frequently regarded as, "incompetent" and "uncaring". ${ }^{21}$ We do not know if such attitudes are shaped, in part, by injury prevention education, but this caveat has been raised with regard to chronic disease prevention. ${ }^{22}$

There is also some evidence that bereaved families try to comfort themselves with assurances that the event which resulted in a fatal injury was, "an accident". ${ }^{23}$ And it has been hypothesized that families who perceived their loved one's death as having been preventable suffer longer and more intense grief. ${ }^{24}$

Also of concern are studies suggesting that: people are less inclined to pay for government programs that prevent deaths from which victims could have protected themselves, ${ }^{25} 26$ the more preventable a hazard is thought to be, the more likely people are to have an optimistic bias with regard to how much it threatens them personally, ${ }^{27}$ and hazards considered to be "controllable" are perceived to be less risky and deserving of strict regulation than are hazards over which people have no control. ${ }^{28}$ These findings point out that preventability beliefs may have complex social ramifications.

\section{Limitations}

This study's major limitation has to do with the degree to which its findings can be generalized. All telephone surveys are subject to noncoverage and non-response.

Non-coverage occurs when some potential subjects are not part of the list, or frame, originally used to enumerate members of the population. ${ }^{29}$ In the United States, only $94 \%$ of households subscribe to telephone service. ${ }^{30}$ Another source of non-coverage in this study was the fact that the sample was generated using list assisted random digit dialing techniques. This method is thought to exclude $2.2 \%$ of households from national samples. ${ }^{31}$ 
Nonresponse arises when potential subjects cannot be located, or when they or a member of their household refuse to take part in a study. ${ }^{29}$ Unfortunately, researchers have noted a definite trend toward increased non-cooperation with phone surveys in recent years. This increase has been attributed in part to more telemarketing, utilization of answering machines, and caller identification devices. When the Council for Marketing and Opinion Research conducted a national telephone survey in 1995 to establish a "benchmark for future measurement of cooperation", they reported a $58 \%$ refusal rate. ${ }^{32}$ Their finding documented a continuing escalation from $42 \%$ (of potential subjects refusing to participate) in 1988 , to $54 \%$ in 1992 . Our study was conducted in the latter half of 1996, and achieved a $62 \%$ refusal rate. (If a proportion of households in which the phone was never answered are presumed eligible and included in the denominator it was $48 \%$.) It should be noted that the present study's protocol required cooperation at both the household (that is person who answered the phone) and respondent (that is random adult selected from among those in the household) level.

Normally no information is available about subjects who refuse to take part in telephone surveys. In this investigation, however, we were able to purchase and compare demographic information about the telephone exchanges (that is first six digits of an American telephone number) of refusers and study participants. This might be interpreted as having information about the two groups' neighborhoods. That analysis revealed that for distributions of age, income, education and race, respondents and refusers were within $2 \%$ points of each other. Of course we cannot know whether nonrespondents were different with regard to any relevant psychosocial variables.

When study participants' self reported demographics were compared with the distribution of the United States population (see table 1), we found considerable similarity. The larger proportion of women in our sample is probably attributable in part to the fact that women are more likely to live in small households than men, and hence have an increased likelihood of being selected to participate in a random digit dialing study. The sources of non-coverage already mentioned probably account for the smaller (than national) proportion of subjects at lower levels of socioeconomic status in our sample. In an attempt to compensate for these discrepancies, the data presented in fig 2 were originally weighted (to national proportions) for gender, household income, and education. Adjusted data are not reported, however, because frequencies changed by only $1.5 \%$ on average (range $0.8-2.3 \%$ ), suggesting that our sample's interpretations may approximate those of the United States' adult population. Additional support for this view may be garnered from how close our results are to those reported by other researchers (see background section).

These findings should certainly not be extrapolated to other cultures, particularly those of developing nations. A number of authors have noted that lay members of non-Western societies embrace notions of injury causation that might be considered "pre-scientific". $33-35$

Finally, this study did not address all of the shortcomings that have been associated with the word accident. For example, it has been observed that accident is used to describe both injuries and the events that produce them. ${ }^{36}$ Missing this distinction may result in missed opportunities to prevent injuries despite an accident's occurrence. It has also been noted that "accident prevention" language recalls an era in which injury control was not recognized - in professional and policy maker circles-as a legitimate public health concern (personal communication, Susan Baker, 1997). This study cannot shed light on the interpretations of those important target audiences, whose reactions are certainly worthy of consideration.

\section{Conclusions}

Calls for abandoning the word accident have been made largely in the absence of empirical evidence. This study offers data to inform this ongoing debate.

The author's intention is not to advocate for increased use of the word accident. Under scrutiny, however, it may prove to have been a red herring; diverting attention away from more important issues. Promoting the advantages of passive interventions, for example, might be more productive than discouraging use of the word accident. Regardless of professional viewpoints on this issue, it seems only responsible to evaluate the intended and unintended consequences of such efforts.

This work was supported in part by a grant from the Lowe's Home Safety Council and the Centers for Disease Control and Prevention grant \# R49/CCR302486. At the time it was carried out, Dr Girasek was a doctoral candidate at Johns Hopkins School of Hygiene and Public Health and the recipient of National Research Service Award \# F31AA05450 from the National Institute on Alcohol Abuse and Alcoholism. Her primary faculty advisor at Johns Hopkins was Dr Andrea Gielen. Dr Girasek gratefully acknowledges Dr Gielen's valuable guidance throughout the course of this study.

The views expressed in this paper are solely those of $\mathrm{Dr}$ Girasek and do not represent any agency of the United States government.

1 Rivara FP. Epidemiology of childhood injuries. In: Matarazzo JD, et al, eds. Behavioral health: a handbook of health enhancement and disease prevention. New York: John Wiley, 1984

2 Rosenberg ML, Rodriguez JG, Chorba TL. Childhood injuries:where we are. Pediatrics 1990;86:1084-91.

3 National Committee for Injury Prevention and Control. Injury prevention: meeting the challenge. New York: Oxford Injury prevention: meeting the

4 National Highway Traffic Safety Administration. "Crashes aren't accidents" campaign. NHTSA Now 1997;3(11):1-2. aren't accidents" campaign. NHTSA Now 1997;3(11):1-2.
Bijur PE. What's in a name? Comments on the use of the terms 'accident' and 'injury'. Inj Prev 1995;1:9.

6 Avery JG. Accident prevention-injury control-injury prevention-or whatever? Inj Prev 1995;1:10-11.

7 Eichelberger MR, Gotschall CS, Feely HB, et al. Parental attitudes and knowledge of child safety: a national survey. Am $\mathcal{F}$ Dis Child 1990;144:714-20.

8 Colver AF, Hutchinson PJ, Judson EC. Promoting children's home safety. BMF 1982;285:1177-80.

9 Roberts H, Smith SJ, Bryce C. Children at risk? Safety as a social value. Buckingham, UK: Open University Press, 1995.

$10 \mathrm{Hu}$ X, Wesson D, Parkin P, et al. Pediatric injuries: parental knowledge, attitudes and needs. Can F Public Health 1996; 87:101-5.

11 Chiappone DI, Kroes WH. Fatalism in coal miners. Psychol Rep 1979;44:1175-80.

12 Green J. Risk and misfortune: social construction of accidents. London: UCL Press, 1997.

13 Suchman EA. A conceptual analysis of the accident phenomenon. Social Problems 1961;8:241-53. 
14 Jobe JB, Mingay DJ. Cognitive research improves questionnaires. Am f Public Health 1989;79:1053-5.

15 Last JM. A dictionary of epidemiology. 3rd Ed. New York: Oxford University Press, 1995.

16 Davison C, Frankel S, Smith GD. "To hell with tomorrow": coronary heart disease risk and the ethnography of fatalism. In: Scott S, et al, eds. Private risks and public dangers. Brookfield, Vermont: Ashgate Publishing in association with British Sociological Association, 1992.

17 Davison C, Smith GD, Frankel S. Lay epidemiology and the prevention paradox: the implications of coronary candidacy for health education. Sociology of Health and Illnes 1991;13:1-19.

18 Finkel KC. Childhood injuries [letter]. Can Med Assoc f 1992;146:1691-2.

19 Berrenberg JL, Rosnik, D. Kravcisin NJ. Blaming the victim: when disease prevention programs misfire. Current Psychology: Research and Reviews 1990-1;9:415-20.

20 Sloan RP, Gruman JC. Beliefs about cancer, heart disease and their victims. Psychol Rep 1983;52:415-24.

21 Frisby ML, Hill JH. A community's response to childhood drownings: a model for accident prevention. Critical Care drownings: a model for accident prevention.

22 Marantz PR. Blaming the victim: the negative consequences of preventive medicine. Am F Public Health 1990;80:11867.

23 Rosenblatt PC, Karis TA. Family distancing following a fatal farm accident. Omega 1993-4;28:183-200.

24 Bugen LA. Human grief: a model for prediction and intervention. Am f Orthopsychiatry 1977;47:196-206.

25 Mendeloff JM, Kaplan RM. Are large differences in "lifesaving" costs justified? A psychometric study of the relative value placed on preventing deaths. Risk Anal 1989; 9:349-63.
26 Beggs SD. Diverse risks and the relative worth of government safety programs: an experimental survey. Report No 700 . Washington, DC: US Environmental Protection Agency, Economic Analysis Division, 23 June, 1984.

27 Weinstein ND. Unrealistic optimism about future life events. F Pers Soc Psychol 1980;39:806-20.

28 Slovic P. Perception of risk. Science 1987;236:280-5.

29 Groves RM. Survey errors and costs. New York: John Wiley, 1989.

30 Belinfante A. Telephone subscribership in the United States. Washington, DC: Federal Communications Commission, Common Carrier Bureau, Industry Analysis Division, October 1997.

31 Giesbrecht LH, Kulp DW, Starer AW. Estimated coverage bias in RDD samples with current population survey data. Presented to the AAPOR Conference and the Centers for Disease Control and Prevention Behavior Risk Factor Surveillance System Conference. May, 1996.

32 Council for Marketing and Opinion Research. Refusal rates and industry image survey. Port Jefferson, New York: Council for Marketing and Opinion Research, 1995.

33 Anazonwu C, Ugwuegbu D. Dimensions of attitudes to automobile accident victims. In: Wilson E, ed. Psychology and society. Ile-Ile, Nigeria: University of Ife Press, 1986.

34 Forjuoh SN. Injury control in developing nations: what can we learn from industrialized countries? Inj Prev 1996;2:901.

35 Ram U. Personal beliefs in accident causes. Indian fournal of Applied Psychology 1986;23:77-80.

36 Langley J. The need to discontinue use of the term "accident" when referring to unintentional injury events. Accid Anal Prev 1988;20:1-8.

\section{Dubai pays drivers}

The rich emirate of Dubai plans to stop motorists- not to give them tickets for traffic violations-but to reward them with cash for safe driving (The Age (Melbourne), October 1998).

\section{Party Safe Across Victoria}

The Party Safe Across Victoria campaign is about ensuring that Victorians enjoy the festive season. In 1997, alcohol contributed to one in four of the lives lost on our roads. Remember that "To party" also means:

- Provide food

- Alternative drinks

- Responsible serving

- Transport

- Your party

Issued by the Community Road Safety Councils of Victoria (Australia) (Herald-Sun, November 1998).

\section{Girl saves baby sister from drowning}

A 10 year old girl is being hailed as a hero after she saved her baby sister from drowning in a backyard pool in Perth. The youngster revived her sister using techniques she learnt from watching television dramas. Sara and her family were whiling Monday afternoon away in the backyard of their Thornlie home when she suddenly noticed her baby sister Tara motionless in the family pool. The toddler had turned blue and stopped breathing. Her mother panicked and went into shock, so Sara immediately began mouth to mouth resuscitation - a process she learnt from watching medical dramas on television. "If I didn't get my sister out of the pool she wouldn't be here right now. I started doing mouth to mouth resuscitation", Sara said. Sara kept the cardiopulmonary resuscitation process up for two or three minutes while her mother rang for an ambulance. Doctors say had it not been for Sara's quick thinking actions, Tara would not be alive today. Mother Aida says her daughter is a hero and has given her the biggest possible Christmas present (Australian Broadcasting Corporation web site, November 1998). 